\title{
Lead aVR in Electrocardiography: Clinical Usefulness
}

\section{Elektrokardiyografide aVR Derivasyonu: Klinik Yararlılığı}

\author{
๑ Mehmet Uzun ${ }^{1}$, ๑ Ata Kırılmaz², ๑ Sabri Kürşad Erinç3 \\ ${ }^{1}$ University of Health Sciences Turkey, Istanbul Sultan 2. Abdülhamid Han Training and Research Hospital, Clinic of Cardiology, Istanbul, Turkey \\ ${ }^{2}$ Maltepe University Faculty of Medicine, Department of Cardiology, ístanbul, Turkey \\ ${ }^{3}$ Beylikdüzü Kolan Hospital, Clinic of Cardiology, İstanbul, Turkey
}

Although the electrocardiogram (ECG) contains 12 leads, lead aVR is frequently neglected and the interpretation is made from the other 11 leads. However, lead aVR may contain valuable information and can influence the decision in many clinical situations. Among these situations, ischemic heart disease and rhythm-conduction disturbances are the leading ones but not limited to these abnormalities. In this paper, various situations in which lead aVR can significantly contribute to the interpretation of the ECG are reviewed.

Keywords: Electrocardiography, aVR, lead

Her ne kadar elektrokardiyogram (EKG) 12 derivasyondan oluşsa da aVR derivasyonu sıklıkla inmal edilmekte ve yorumlama diğer 11 derivasyon üzerinden yapılmaktadır. Bununla birlikte, aVR derivasyonu da değerli bilgiler içerebilir ve birçok klinik durumda tanıya etki edebilir. Bu durumlar arasında iskemik kalp hastalıkları ve ritim-iletim bozuklukları başta gelmektedir, ancak bu durumlarla sınırlı değildir. Bu yazıda, aVR'nin EKG yorumlanmasına önemli katkıda bulunabileceği çeşitli durumlar gözden geçirilmiştir.

Anahtar Kelimeler: Elektrokardiyografi, aVR, derivasyon

\section{Introduction}

Since the first recording of the electrical activity of the heart by Einthoven, the electrocardiogram (ECG) has been an essential diagnostic tool in cardiology (1). After the addition of augmented leads by Goldberger, the ECG has been standardized as a 12 lead-ECG with recording from 10 different sites (2). However, in a study by Pahlm et al. (3) lead aVR was reversed to its mirror image and interpreters were asked to interpret the 12-lead surface ECG. The results showed that $80-94 \%$ of interpreters had not detected when lead aVR was reversed (3). It was apparent that most of the interpreters were neglecting lead aVR. However, lead aVR may provide important information about the heart. In this review, some of the instances where lead aVR may play an important role in the diagnosis are presented under the subtitles of ischemic heart disease, rhythm-conduction abnormalities, and miscellaneous conditions (Table 1).

\section{Ischemic Heart Disease}

In acute myocardial infarction, lead aVR may help to predict the occlusion site of culprit coronary artery. ST segment elevation or depression or $\mathrm{R}$ wave slurring in lead aVR may have some implications. It has been suggested that in acute inferior myocardial infarction, the absence of $>1 \mathrm{~mm}$ ST depression in lead aVR is $93 \%$ specific for root cause analysis occlusion as the culprit artery (4). If the ST depression is $\geqslant 1 \mathrm{~mm}$, the culprit artery is left circumflex artery with a specificity of $80 \%$ and sensitivity of $96 \%$. However, this needs to be further evaluated because of contradicting data. Baptista et al. (5) have reported that ST depression in lead aVR is not superior to classical criteria, which were accepted as ST depression in lead DI; ST depression in

Address for Correspondence: Mehmet Uzun, University of Health Sciences Turkey, İstanbul Sultan 2. Abdülhamid Han Training and Research Hospital,

Clinic of Cardiology, İstanbul, Turkey

Phone: +90 5323175202 E-mail: muzun2009@gmail.com ORCID ID: orcid.org/0000-0003-2999-489X

Received: 09.08.2020 Accepted: 17.09.2020 
leads V1 and V2, ST elevation in lead DIII > DII, ST depression in V3/ST elevation in DIII ratio >1.2. Different definition of the infarct related artery, which was defined as the artery with the most severe lesion, may explain the difference. Another method for evaluating ST segment changes in lead aVR is comparison with lead V1. The simultaneous impairment of blood flow in both the left circumflex and the left anterior descending artery could make the ST-segment vector more perpendicular to V1, resulting in less elevation of ST-segment in lead V1. In accordance with this hypothesis, Yamaji et al. (6) have found that greater ST-elevation in aVR than in V1 is $81 \%$ sensitive and $80 \%$ specific for left main coronary artery disease $(4,7)$. Another explanation for the ST elevation in lead aVR could be the involvement of the basal septum by acute MI. The lead aVR faces the basal septum more than any other lead. Therefore, the involvement of basal septum, which has dual perfusion from both the right coronary artery and the left anterior descending artery, may result in ST elevation in lead aVR.

The perfusion from the left anterior descending artery is mediated through the first septal branch. The occlusion of the first septal branch or the left anterior descending artery proximal to the first septal branch may also cause ST elevation in lead aVR. This hypothesis was confirmed by Aygül et al. (8) and Engelen et al. (9), who found that ST elevation in aVR in acute myocardial infarction was predictive of left anterior descending artery occlusion proximal to the first septal perforator branch. However, due to dual perfusion of basal septum, ST elevation in aVR in acute anterior myocardial infarction should suggest multivessel disease or left main coronary artery disease that prevents collateral perfusion. In fact, the relation between ST

\section{Table 1. Areas where lead aVR can be helpful}

\section{A. Ischemic heart disease}

a. Prediction of culprit artery in acute myocardial infarction

b. Estimating the extension of acute myocardial infarction

c. Assessment of prognosis in acute myocardial infarction

d. Evaluation of exercise electrocardiography

\section{B. Rhythm and conduction abnormalities}

a. Diagnosis of left anterior hemiblock, complete or incomplete right bundle branch block

b. Prediction of origin of ventricular arrhythmia

c. Prediction of origin of supraventricular arrhythmia

d. Prediction of arrhythmia in hypertrophic cardiomyopathy or intoxication of tricyclic antidepressants

\section{Miscellaneous conditions}

a. Diagnosis of electrode misplacement

b. Rotation of heart

c. Right ventricular hypertrophy

d. Acute pericarditis

e. Hypertrophic cardiomyopathy

f. Postpartum cardiomyopathy

g. Acute pulmonary embolism elevation in aVR and multivessel or left main coronary disease has been reported $(10,11,12,13)$. Kosuge et al. (14) have also studied the utilization of lead aVR in predicting patients who are candidate for surgery of angioplasty. This discrimination is important since clopidogrel loading is beneficial in patients who will undergo angioplasty while it may be harmful for patients who will be surgically treated.

Another hypothesis about the ST elevation in lead aVR is that lead $\mathrm{aVR}$ is the reversal of leads $\mathrm{V} 5$ and $\mathrm{V} 6$, and therefore, any situation that causes ST depression in V 5 and $\mathrm{V} 6$ could cause ST elevation in lead aVR. An example is the anterolateral subendocardial ischemia, which may cause reciprocal ST elevation in lead aVR as well as ST depression in leads V5 and V6 $(15,16)$. According to this hypothesis, occlusion of the first diagonal branch may also cause ST elevation in aVR (17). There is also the possibility that the ST elevation in lead aVR in the study of Sclarovsky et al. (18) might have resulted from occlusion of first diagonal branch by emboli coming from the thrombus in the left main coronary artery. Also, the study by Martínez-Dolz et al. (19) demonstrated that $\geqslant 0.5$ $\mathrm{mm}$ ST elevation in aVR is $90 \%$ specific for predicting the involvement of first diagonal branch or first septal perforator branch (including occlusions proximal to these branches). However, it was also noted that sensitivity was only $29 \%$. The common feature of all these studies of acute anterior myocardial infarctions is that the ST elevation in lead aVR has high specificity but low sensitivity for predicting the occlusion site.

Recognition of the extension of an acute myocardial infarction is important in the prognosis of the disease. The lead aVR may also be helpful in estimating the infarct area. The lead $-a V R$ is frequently used for this purpose. In conventional ECG, precordial leads V1 to V6 show an orderly progression in waveform morphology. On the other hand, there is a gap in the sequential order of frontal leads. Although there is $30^{\circ}$ angle between lead $\mathrm{aVL}$ and I and between leads II and aVF or leads aVF and III, the angle between lead I and II is $60^{\circ}$ and angle between leads III and aVR is $90^{\circ}$. The mirror image of lead aVR may alleviate these gaps because it is $30^{\circ}$ apart from both lead II and I. Besides, the use of lead -aVR may enable the interpreters to evaluate the frontal leads in a sequential order; aVL, lead I,-aVR, lead II, aVF and lead III. From this point of view, ST elevation in -aVR may show lateral involvement in inferior myocardial infarctions and inferior involvement in lateral myocardial infarctions (20).

The degree of ST-segment depression is also important. In patients with anterolateral myocardial infarction, $\geqslant 0.5 \mathrm{~mm}$ ST-segment depression in aVR is an independent predictor of predischarge left ventricular ejection fraction $<35 \%$ despite successful reperfusion (21). In such patients, the need for intraaortic balloon pump and percentage of TIMI flow grade 
0-1 are more frequent. If the depression in aVR exceeds $1 \mathrm{~mm}$ in patients with inferior myocardial infarction, myocardial reperfusion is 8.41 times less likely to have occurred (22). The slurring of $R$ wave in lead aVR is $70 \%$ sensitive and $93 \%$ specific for right ventricular involvement in acute posterior wall myocardial infarction (23).

In an analysis of The Tampere Acute Coronary syndrome (24) study, a positive T-wave in lead aVR was associated with higher 10-year mortality. The authors argued that positive T-wave in aVR could represent an unfavorable post myocardial infarction remodeling.

Lead aVR can also be used in the interpretation of exercise ECG. It has been reported that ST elevation in aVR accompanying ST depression in V5 is $50 \%$ sensitive and $92 \%$ specific for predicting left main or proximal left anterior descending artery

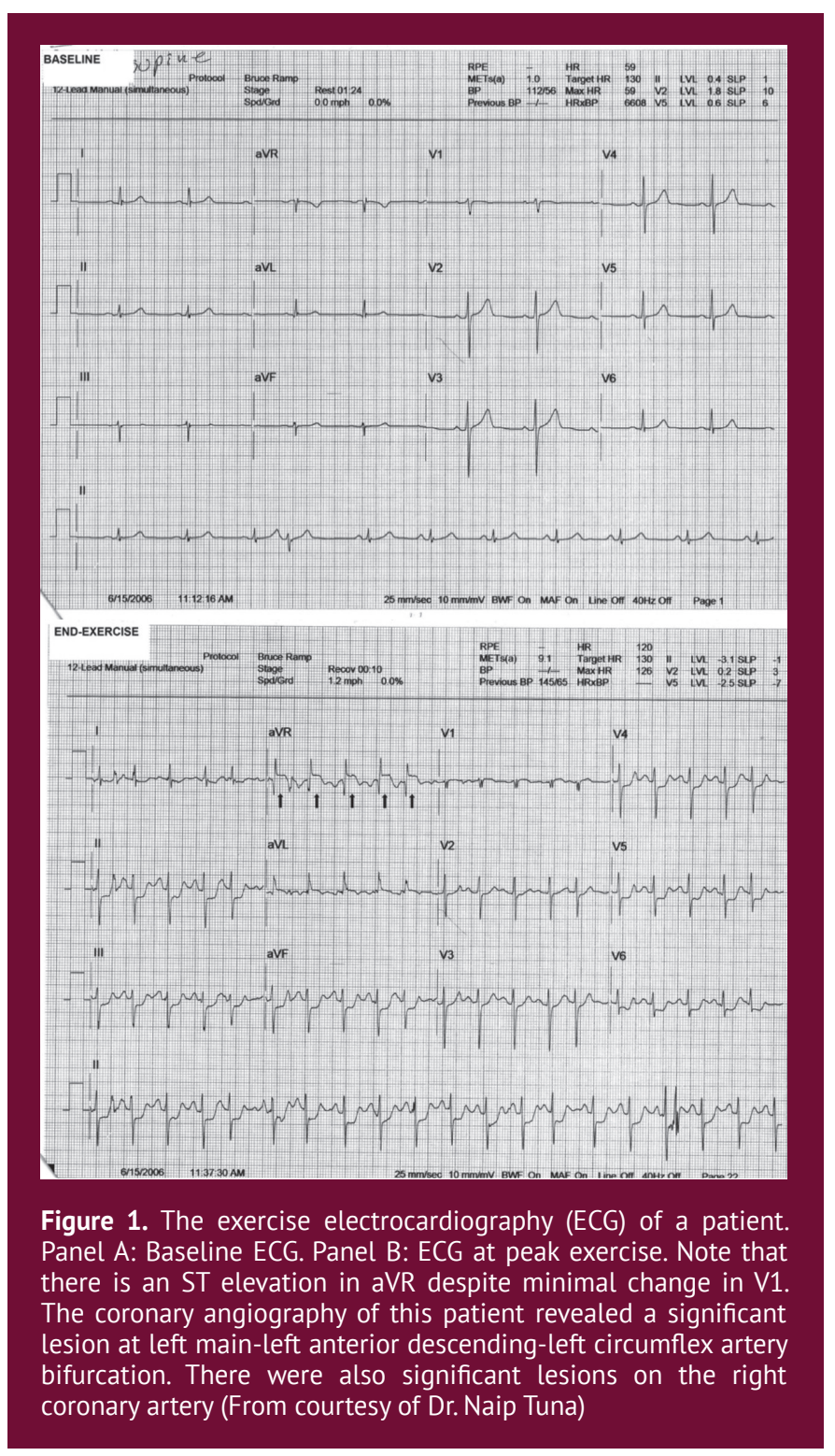

stenosis or multivessel disease (25) (Figure 1). ST changes during the recovery phase are also important. Inclusion of aVR to interpretation can increase the accuracy of the test $(26,27)$. Furthermore, inversion of positive T-waves in aVR during exercise test suggests myocardial viability in patients with Q-wave myocardial infarction (28).

\section{Rhythm and Conduction Abnormalities}

Potential use of aVR in the assessment of rhythm and conduction abnormalities is usually complementary. In left anterior hemiblock, the presence of terminal $R$ wave in aVR and the terminal $R$ wave peak in aVR occurring later than that in $\mathrm{aVL}$ is diagnostic (29). In the diagnosis of right bundle branch block, lead aVR is not usually used but the presence of $Q R$ or rSR' pattern in aVR is supportive.

The importance of aVR has increased after the introduction of electrophysiology to routine practice. During electrophysiological studies of ventricular tachycardia, accurate prediction of the origin of the premature beats is extremely important for reducing radiation time. It is frequently difficult to differentiate the origin of tachycardia between right ventricular outflow tract and pulmonary artery. In tachycardia originating from pulmonary artery, the ratio of the amplitude of Q-wave in aVR to the amplitude of Q-wave in aVL is increased (Figure 2) (30). However, this finding is also present in ventricular tachycardia originating from posterolateral portion of the right ventricular outflow tract (31). The QRS wave duration in lead aVR may be an important predictor for successful ablation of ventricular tachycardia or ventricular premature beats originating from right ventricular outflow tract. The duration of QRS wave in lead aVR was found to be inversely related to the success of ablation (32).

The QRS deflection may help delineate the origin of ventricular premature depolarizations. Barmeda et al. (33) have found in a study with small sample size that the origin of the ventricular premature depolarization is more likely to be basal septal or basal left ventricle if $Q R S$ deflection in aVR is opposite with $\mathrm{aVL}$, while it is more likely to be other sites of the left ventricle if they are in the same direction.

The lead aVR may also help in differential diagnosis of narrow complex tachycardia. The ST elevation in aVR is seen in $71 \%$ of atrioventricular reentrant tachycardia, $31 \%$ of atrioventricular nodal reentrant tachycardia and $16 \%$ of atrial tachycardia (34). Therefore, ST elevation in aVR suggests that it is a reentrant tachycardia involving the atrioventricular node. In a study by Kuo et al. (35), it was shown that $p$ wave polarity was negative in all patients with paroxysmal atrial tachycardia originating from the superior vena cava or right upper pulmonary vein. The distinction between these two is possible after the assessment of $\mathrm{V} 1$ and aVL. The polarity of 
p-wave in aVR may also be helpful in locating the origin of right atrial tachycardia. The negative polarity of $p$-wave is $100 \%$ sensitive and $93 \%$ specific in identifying tachycardia originating from crista terminalis in patients with right atrial tachycardia (36). The lead aVR may also be used in differentiating upper loop reentry from typical atrial flutter. The amplitude of flutter wave is significantly lower in upper loop reentry than in typical atrial flutter (37).

The configuration of QRS in aVR may also help in predicting future cardiac arrhythmias. There are at least two types of patients for whom this might be helpful: patients with hypertrophic cardiomyopathy and patients with tricyclic antidepressant intoxication. In patients with hypertrophic cardiomyopathy, positive QRS wave in aVR is a predictor for inducible ventricular tachycardia (38). These patients are at greater risk for future sudden death. Arrhythmia is also an important problem for patients with tricyclic antidepressant intoxication. The most powerful electrocardiographic predictor of future arrhythmia and seizure is suggested to be $R$ wave amplitude $\geqslant 3 \mathrm{~mm}$ in aVR (39). Buckley et al. (40) compared

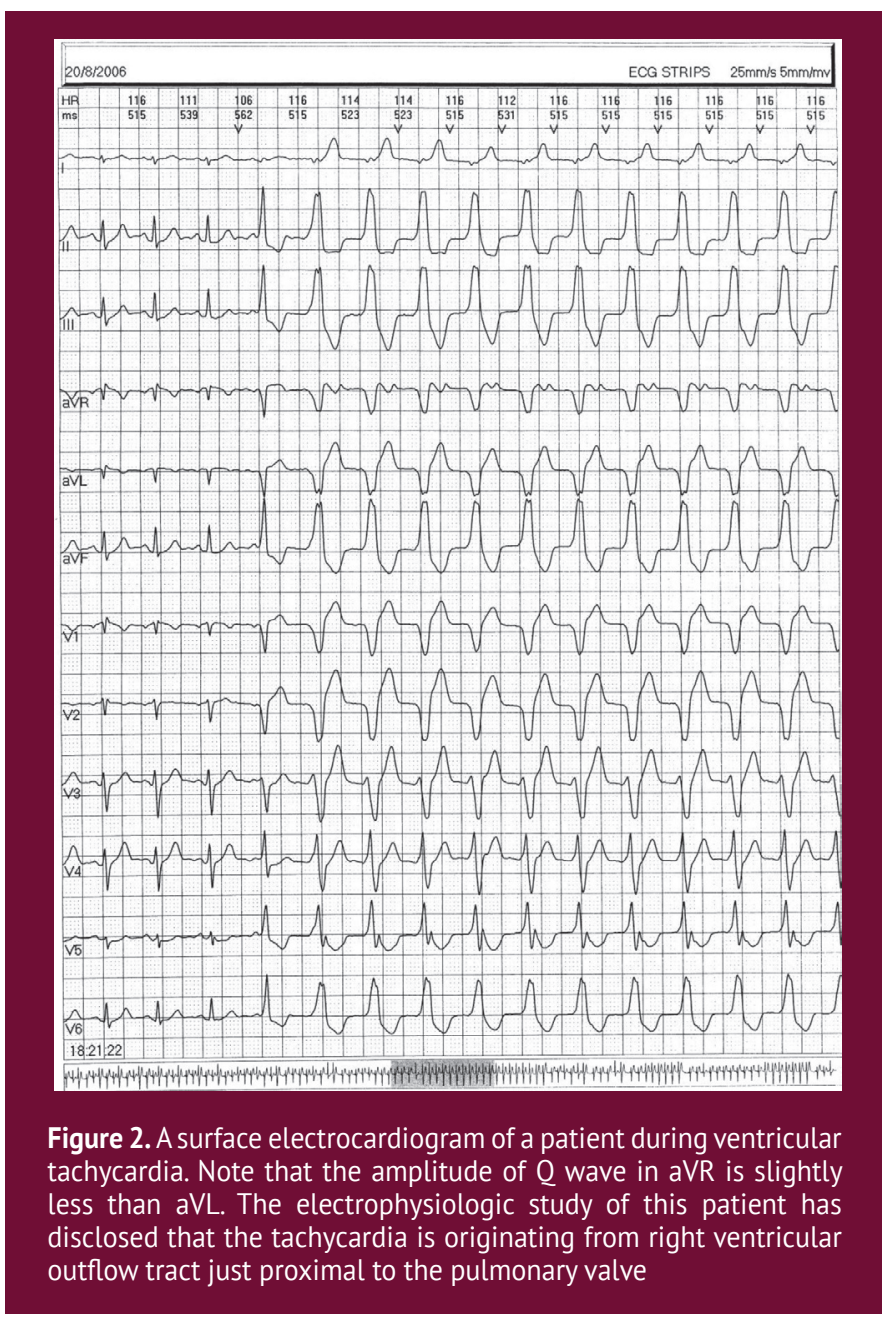

various criteria and found that the criterion of $\mathrm{R} / \mathrm{S}>0.7$ in $\mathrm{aVR}$ is the most powerful predictor. However, its low negative predictive value (41\%) must be compensated by using other criteria.

\section{Miscellaneous Conditions}

The misplacement of electrocardiographic leads is a major problem for the interpreters of the ECG. If not recognized, it may result in erroneous diagnosis and inappropriate management. Ho and Ho (41) have developed an algorithm to uncover the misplacement of electrocardiographic leads not involving the right leg lead. According to this algorithm, the evaluation begins with the localization of the true aVR. In this algorithm, aVR may show the configuration of aVF or $\mathrm{aVL}$. The similarity of QRS configuration to any other limb lead must prompt the interpreter to take lead misplacement into consideration (Figure 3).

The displacement of the heart itself is also a frequent problem in interpretation. The $Q R$ pattern in aVR should suggest the prominent clockwise rotation of the heart, while the QS or $\mathrm{rS}$ pattern is suggestive of intermediate clockwise rotation.

In the diagnosis of right ventricular hypertrophy, aVR is not routinely used because of its low specificity. However, when the other findings are not conclusive, aVR may provide supportive data. The $Q R$ pattern in aVR is found in type A right ventricular hypertrophy. It should be kept in mind that this finding is also found in clockwise rotation of the heart, backward displacement of apex, incomplete or complete right bundle branch block and inferolateral myocardial infarctions.

Acute pericarditis is characterized by ST elevation in all leads except for aVR, which usually reflects reciprocal changes. The electrocardiographical signs of acute pericarditis change according to the stage. In all stages, the aVR shows opposite changes, i.e. ST segment depression, $T$ wave negativity and positivity and PR segment elevation $(42,43)$.

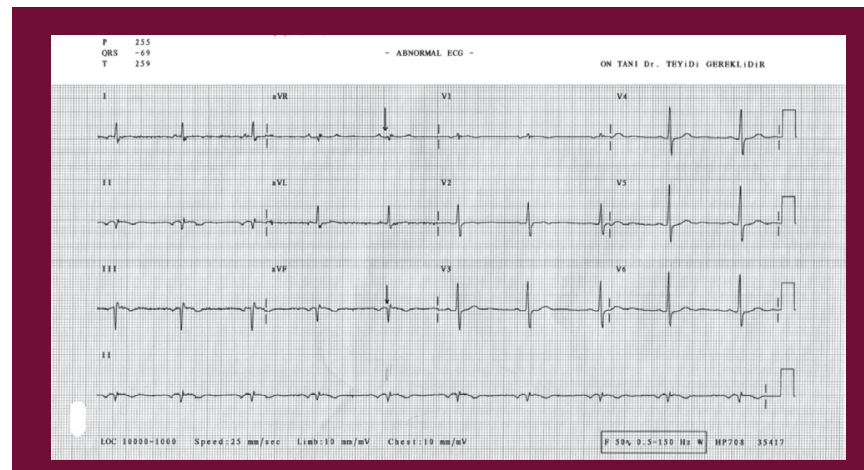

Figure 3. A surface electrocardiogram of a normal patient. Note that true aVR configuration (negative $p$ wave, negative QRS and negative $T$ wave) is seen on lead aVF. This finding suggests that leads of right arm and left leg are confused 
Hypertrophic cardiomyopathy is usually characterized by left ventricular hypertrophy. Right ventricular involvement is very rare. In a few cases of the involvement of anterobasal wall of right ventricle, $R$ wave amplitude in aVR was noted to be increased (44).

Ekizler et al. (45) has investigated the prognostic role of lead aVR in postpartum cardiomyopathies in 82 patients. They have found that T-wave amplitude in lead aVR predicted primary endpoint, which was defined as was defined as cardiac death, arrhythmic events, or persistent left ventricular systolic dysfunction, with a sensitivity of $100 \%$ and specificity of $100 \%$. In a study by Yelgeç on acute pulmonary embolism patients, mortality was higher in patients presenting with positive T-wave in lead aVR. This finding was also related to lower systolic blood pressure, which means that the disease was more severe in such patients.

\section{Highlights}

- Lead aVR is important in a wide variety of cardiac disease.

- In interpreting lead aVR, QRS deflection,ST segment elevation and direction of T-wave are important.

- Changes in lead aVR in ischemic heart diseases are usually indicative of more severity and worse prognosis.

\section{Conclusion}

The 12-lead ECG must be interpreted as a whole. No lead should be overlooked during interpretation. Lead aVR must be included in the analysis of the ECG. It has special importance in various cardiac conditions, including acute myocardial infarction, arrhythmias, conduction defects and electrode misplacements.

\section{Acknowledgment}

We sincerely appreciate Prof. Dr. Naip Tuna, for his permission for using his courtesy. We have learned that he had passed away a couple of years ago.

Peer-review: Externally peer-reviewed.

\section{Authorship Contributions}

Concept: M.U., A.K., S.K.E., Literature Search: M.U., A.K., S.K.E., Writing: M.U., A.K., S.K.E.

Conflict of Interest: No conflict of interest was declared by the authors.

Financial Disclosure: The authors declared that this study received no financial support.

\section{References}

1. Rivera-Ruiz M, Cajavilca C, Varon J. Einthoven's string galvanometer: the first electrocardiograph. Tex Heart Inst J. 2008;35:174-178. [Pubmed]
2. A simple, indifferent, electrocardiographic electrode of zero potential and a technique of obtaining augmented, unipolar, extremity leads. Am Heart J. [Crossref]

3. Pahlm US, Pahlm O, Wagner GS. The Standard 11-lead ECG. Neglect of lead aVR in the classical limb lead display. I Electrocardiol. 1996;29(Suppl):270-274. [Crossref]

4. Nair A, Glancy L. ECG discrimination between right and left circumflex arterial occlusion in patients with acute inferior infarction: Value of old criteria and use of lead aVR. Chest. 2002;122:134-139. [Crossref]

5. Baptista SB, Farto e Abreu P, Loureiro JR, Thomas B, Nédio M, Gago S, et al. Electrocardiographic identification of the infarct-related artery in acute inferior myocardial infarction. Rev Port Cardiol. 2004;23:963-971. [Pubmed]

6. Yamaji H, Iwasaki K, Kusachi S, Murakami T, Hirami R, Hamamoto $H$, et al. Prediction of acute left main coronary artery obstruction by lead 12lead electrocardiography: ST-segment elevation in lead aVR with less ST-segment elevation in lead V1. J Am Coll Cardiol. 2001;38:1348-1354. [Crossref]

7. Misumida N, Kobayashi A, Fox JT, Hanon S, Schweitzer P, Kanei Y. Predictive value of ST-segment elevation in lead aVR for left main and/or threevessel disease in non-ST-segment elevation myocardial infarction. Ann Noninvasive Electrocardiol. 2016;21:91-97. [Crossref]

8. Aygül N, Özdemir K, Tokaç M, Aydın MÜ, Vatankulu MA. Predictive value of lead aVR for lesions in the proximal portion of the left anterior descending coronary artery. Türk Kardiyol Dern Arş. 2006;34:154-161. [Link]

9. Engelen DJ, Gorgels AP, Cheriex EC, De Muinck ED, Ophuis AJO, Dassen WR, et al. Value of the electrocardiogram in localizing the occlusion site in the left anterior myocardial infarction.J Am Coll Cardiol.1999;34:389-395. [Crossref]

10. Kosuge M, Kimura K, Ishikawa T, Ebina T, Shimizu T, Hibi K, et al. Predictors of left main or three-vessel disease in patients who have acute coronary syndromes with Non-ST-segment elevation. Am J Cardiol. 2005;95:13661369. [Crossref]

11. Rostoff P, Piwowarska W, Konduracka E, Libionka A, Bobrowska-Juszczuk M, Stopyra K, et al. Value of aVR in the detection of significant left main coronary artery acute coronary syndrome. Polish Heart J. 2005;62:128-132. [Pubmed]

12. Akpinar $\mathrm{O}$, Kanadaşi M, Açikalin A, Acartürk E. ST elevation in aVR could be a sign of the left main coronary artery lesion. Anadolu Kardiyol Derg. 2002;2:349. [Pubmed]

13. Gorgels AP, Engelen DJ, Wellens HJ. Lead aVR, a mostly ignored but very valuable lead in clinical electrocardiography. J Am Coll Cardiol. 2001;38:1355-1356. [Crossref]

14. Kosuge M, Ebina T, Hibi K, Morita S, Endo M, Maejima N, et al. An early and simple predictor of severe left main and/or three-vessel disease in patients with non-ST-segment elevation acute coronary syndrome. Am J Cardiol. 2011;107:495-500. [Crossref]

15. Assali A, Sclarovsky S, Hertz I, Vaturi M, Gilad I, Solodky A, et al. Persistent ST-segment depression in precordial leads V5-V6 after Q-wave anterior wall myocardial infarction is associated with restrictive physiology of the left ventricle.J Am Coll Cardiol. 2000;35:352-357. [Crossref]

16. Levine HD, Ford RV. Subendocardial infarction: report of six cases and survey of the literature. Circulation. 1950;1:246-263. [Crossref]

17. Sclarovsky S, Birnbaum Y, Solodky A, Zafrir N, Wurzel M, Rechavia E. Isolated mid-anterior myocardial infarction: a special electrocardiographic subtype of acute myocardial infarction with ST elevation in nonconsecutive leads and two different morphological types of STdepressions. Int J Cardiol. 1994;46:37-47. [Crossref]

18. Sclarovsky S, Kjell N, Birnbaum Y. Manifestation of left main coronary artery stenosis is diffuse ST depression in inferior and precordial leads on ECG (Letter to the Editor). J Am Coll Cardiol. 2002;40:575-576. [Crossref] 
19. Martínez-Dolz L, Arnau MA, Almenar L, Rueda J, Osa A, Quesada A, et al. Usefulness of the electrocardiogram in predicting the occlusion site in acute anterior myocardial infarction with isolated disease of the left anterior descending coronary artery. Rev Esp Cardiol (English Edition). 2002;55:1036-1041. [Crossref]

20. Menown I,Adgey A. Improving the ECG classification of inferior and lateral myocardial infarction by inversion of lead aVR. Heart. 2000;83:657-660. [Crossref]

21. Kosuge M, Kimura K, Ishikawa T, Endo T, Hongo Y, Shigemasa T, et al. ST segment depression in lead aVR predicts predischarge left ventricular dysfunction in patients with reperfused anterior acute myocardial infarction with anterolateral ST-segment elevation. Am Heart J. 2001;142:51-57. [Crossref]

22. Kosuge M, Kimura K, Ishikawa T, Ebina T, Hibi K, Toda N, et al. ST-segment depression in lead aVR: a useful predictor of impaired myocardial reperfusion in patients with inferior acute myocardial infarction. Chest. 2005;128:780-786. [Crossref]

23. Mittal SR, Jain S. Electrocardiographic diagnosis of right ventricular infarction in the presence of left ventricular posterior infarction. Int J Cardiol. 1999;68:125-128. [Crossref]

24. Siren M, Koivula K, Eskola MJ, Martiskainen M, Huhtala H, Laurikka J, et al. The prognostic significance of a positive or isoelectric T wave in lead aVR in patients with acute coronary syndrome and ischemic ECG changes in the presenting ECG-Long-term follow-up data of the TACOS study. Journal of Electrocardiology. 2020;60:131-137. [Crossref]

25. Michaelides AP, Psomodaki ZD, Richter DJ, Dilaveris PE, Andrikopoulos GK, Stefanadis C, et al. Significance of exercise-induced simultaneous ST-segment cahnges in lead aVR and V5. Int J Cardiol. 1999;71:49-56. [Crossref]

26. Kronander H, Fischer-Colbrie W, Nowak J, Brodin LÅ, Elmqvist H. Improved capacity of exercise electrocardiography in the detection of coronary artery disease by focusing on diagnostic variables during the early recovery phase.J Electrocardiol. 2005;38:130-138. [Crossref]

27. Viik J, Lehtinen R,Turjanmaa V, Niemela K, Malmivuo J. Corrrect utilization of exercise electrocardiographic leads in differentiation of men with coronary artery disease from patients with a low likelihood of coronary artery disease using peak exercise ST-segment depression. Am J Cardiol. 1998;81:964-969. [Crossref]

28. Altun A, Durmus-Altun G, Birsin A, Gultekin A, Tatli E, Ozbay G. Normalization of negative $T$ waves in the chronic stage of $Q$ wave anterior myocardial infarction as a predictor of myocardial viability. Cardiology. 2005;103:7378. [Crossref]

29. Warner RA, Hill NE,Mookherjee S, Smulyan H. Improved electrocardiographic criteria for the diagnosis of left anterior hemiblock. Am J Cardiol. 1983;51:723-726. [Crossref]

30. Sekiguchi Y, Aonuma K, Takahashi A, Yamauchi Y, Hachiya H, Yokoyama $\mathrm{Y}$, et al. Electrocardiographic and electrophysiologic characteristics of ventricular tachycardia originating within the pulmonary artery. J Am Coll Cardiol. 2005;45:887-895. [Crossref]

31. Yoshida Y, Hirai M, Murakami Y, Kondo T, Inden Y, Akahoshi M, et al. Localization of precise origin of idiopathic ventricular tachycardia from the right ventricular outflow tract by a 12 lead ACG: a study of pace mapping using a multielectrode "basket" catheter. Pacing Clin electrophysiol. 1999;22:1760-1768. [Crossref]

32. Vestal M, Wen MS, Yeh SJ, Wang CC, Lin FC, Wu D. Electrocardiographic predictors of failure and recurrence in patients with idopathic right ventricular outflow tract tachycardia and ectopy who underwent radiofrquency catheter ablation. J Electrocardiol. 2003;36:327-332. [Crossref]

33. Barmeda M, Jain R, Gautam S, Mar PL, Devabahktuni SR, Stucky MA, et al. Novel electrocardiographic criteria for diagnosis of premature ventricular complexes arising from the base of left ventricle. J Electrocardiol. 2020;60:148-150. [Crossref]

34. Ho YL, Lin LY, Lin JL, Chen MF, Chen WJ, Lee YT, et al.Usefulness of ST-segment elevation in lead aVR during tachycardia for determining the mechanism of narrow QRS complex tachycardia. Am J Cardiol. 2003;92:1424-1428. [Crossref]

35. Kuo JY, Tai CT, Tsao HM, Hsieh MH, Tsai CF, Lin WS, et al. P wave polarities of an arrhytmogenic focus in patients with paroxysmal atrial fibrillation originating from superior vena cava or right superior pulmonary vein. J Cardiovasc Electrophysiol. 2003;14:350-357. [Crossref]

36. Tada H, Nogami A, Naito S, Suguta M, Nakatsugawa M, Horie Y, et al. Simple electrocardiographic criteria for identifying the site of origin of focal right atrial tachycardia. Pacing Clin Electrophysiol. 1998;21:2431-2439. [Crossref]

37. Yuniadi $Y$, Tai $C T$, Lee $K T$, Huang $B H$, Lin YJ, Higa S, et al. A new electrocardiographic algorithm to differentiate upper loop re-entry from reverse typical atrial flutter.J Am Coll Cardiol. 2005;46:524-528. [Crossref]

38. Watson RM, Schwartz JL, Maron BJ, Tucker E, Rosing DR, Josephson ME. Inducible polymorphic ventricular tachycardia and ventricular fibrillation in a subgroup of patients with hypertrophic cardiomyopathy at high risk for sudden death.J Am Coll Cardiol. 1987;10:761-774. [Crossref]

39. Liebelt EL, Francis PD, Woolf AD. ECG lead aVR versus QRS interval in predicting seizures and arrhytmias in acute tricyclic antidepressant toxicity. Ann Emerg M. 1995;26:195-201. [Crossref]

40. Buckley NA, Chevalier S, Leditschke IA, O'Connell DL, Leitch J, Pond SM. The limited utility of electrocardiography variables used to predict arrhythmia in psychotropic drug overdose. Crit Care. 2003;7:R101. [Crossref]

41. Ho KK, Ho SK. Use of the sinus $P$ wave in diagnosing elestrocardiographic limb led misplacement not involving the right leg (ground) lead. J Electrocardiol. 2001;34:161-171. [Crossref]

42. Soffer A. Electrocardiographic abnormalities in acute convalascent nd recurrent stages of idiopathic pericarditis. Am Heart J. 1960;60:729-738. [Crossref]

43. Chew HC, Lim SH. Electrocardiographical case. ST elevation: is this an infarct? Pericarditis. Singapore Med J. 2005;46:656-660. [Pubmed]

44. Matsubara T, Yamazoe M, Kimura M, Hori T, Ozaki K, Hatada K, et al. Hypertrophic cardiomyopathy with dominant hypertrophy in the right anterobasal region of the ventricular septum: a case report. J Cardiol. 2000;36:45-48. [Pubmed]

45. Ekizler FA, Cay S, Kafes H, Ozeke O, Ozcan F, Topaloglu S, et al. The prognostic value of positive T wave in lead aVR: A novel marker of adverse cardiac outcomes in peripartum cardiomyopathy. Ann Noninvasive Electrocardiol. 2019;24:e12631. [Crossref] 